\title{
Spectrum of Complications in Post Liver Transplant Patients. A Study of 30 Cases
}

\author{
Aftab Ahmed Siddiqui, Rakhshinda Jabeen, Moin Ahmed Ansari, B abar B ashir, \\ Saeed Ahmed and Masoud Bakheet Khashoob
}

\begin{abstract}
OBJECT: To study the complications encountered in post liver transplant patients performed due to different etiologies leading to end stage liver disease.

STUDY DESIGN: Cohort and observational study.

PLACE AND DURATION OF STUDY: Sultan Qaboos University Hospital, Oman. From Dec 2001July 2006.

PATIENTS AND METHODS: The study was conducted on all patients having cadavaric liver transplantation outside Oman. All patients were followed up for at least 18 months after enrolling in the study. They all had certain routine tests at the start of the study and were repeated according to the requirement of the individual patients. All patients had tacrolimus as an immunosuppressive agent. Patients with hepatitis B had hepatitis B immunoglobulin, alongwith lamivudine for relapse prophylaxis.

RESULTS: Complications of liver transplantation was observed in 21 patients, out of total 30 patients. Thirteen patients developed new onset diabetes mellitus, among them 7 had other complications as well. Eight patients had different hepatic complications and 7 had non hepatic problems. Total 5 patients expired during our follow up.

CONCLUSION: The complications of liver transplantation can be controlled and managed if diagnosed promptly and treated early.
\end{abstract}

KEY WORDS: Cadavaric liver transplantation, End stage liver disease, Tacrolimus, Hepatic complications, Non- Hepatic complications.

\section{INTRODUCTION}

The most effective therapy for end stage liver disease is transplantation. Improved surgical techniques and the introduction of new immunosuppressive agents have enhanced the longterm results of liver transplantation. In 1960's, Starzl and his group carried out the first successful hepatic transplantation in humans. ${ }^{1}$ Since the early 1980's, there has been a consistent improvement in the results of liver transplantation and currently one year survival is almost $80 \% .^{2}$ Liver transplantation is indicated in both children and adults, who, in the absence of contraindications suffer from severe, irreversible liver disease for which alternative medical or surgical treatment is not available. The major indications in children are biliary atresia, inherited or genetic disorders of metabolism associated with liver failure, Criggler Najjar disease type I, homozygous familial hypercholesterolemia and hemophilia.,4 The main indications in adults are end stage cirrhosis of all causes, sclerosing cholangitis, Caroli's disease, recurrent infection and sepsis associated with inflammatory and fibrotic obstruction of the biliary tree, schistosomiasis, idiopathic hepatic fibrosis, giant hemangioma. $^{3}$ The absolute contraindications of liver transplantation are disseminated malignancy, severe cardiac or pulmonary disease, chaotic behavior (patients with drugs like heroin addiction, alcoholism who failed to abstain), and acquired immunodeficiency syndrome. ${ }^{3}$ Most liver donations are from a brainstem dead (cadaveric) adult donor. Due to the paucity of donor liver live related liver is used as well. ${ }^{5}$ Allocation of liver to the recipient is based on Child Turcott Pugh (CTP) score ${ }^{6}$ and model for end stage liver disease (MELD) score. ${ }^{7,8}$ CTP score includes five clinical variables: encephalopathy stage, ascites, bilirubin, albumin and prothrombin time. MELD score is based upon a mathematical score includes bilirubin, creatinine and prothrombin time expressed as international normalized ratio. ${ }^{3}$ The average surgical time is $8 \mathrm{hr}$. After transplantation all patients received immmunsuppressive therapy. It may either be cyclosporine or tacrolimus. Complications of liver transplantation can be divided into hepatic or non-hepatic categories. Immediate non-hepatic complications include renal dysfunction, pre-renal azotemia, acute renal injury, aplastic anemia, bacterial, fungal or viral infections and neuropsychiatric complications. Longterm non-hepatic complications after liver transplantation are attributable 
primarily to immunosuppressive therapy, besides diabetes mellitus, hypertension, hyperlipidemia and chronic renal insufficiency. ${ }^{9}$ Hepatic complications include primary graft failure, vascular compromise, failure or obstruction of the biliary anastomosis and rejection, and the relapse of the viral hepatitis $B \& C^{10}$ The focus of this study was to observe the course and prognosis in post liver transplant in Omani patients and highlighting the complications encountered in these patients.

\section{PATIENTS AND METHODS}

The study was conducted at Sultan Qaboos University Hospital, Oman during the period of Dec 2001 to July 2006. It was a cohort, non-randomized and observational study. Between Dec 2001 to Dec 2004, 30 patients were included in the study, who had cadavaric liver transplantation at Tianjin first central hospital, Tianjin China. Patients were received between 1-3 months of transplantation. Patients who enrolled early in the study were followed up for 5 years whereas the last patient enrolled in the study was followed up for 18 months, thus majority of the patients were followed up for more than three and half years. Among 30 patients 23 were males and 7 were females. The age range among male patients was 18-65 years, while in female patients it was 32-45 years. All patients received to the hospital had certain immediate investigations including complete blood count, coagulation profile, liver function test, urea, creatinine, electrolytes, blood sugar and tacrolimus levels. All patients also had baseline Magnetic resonance cholangiopancreatiography, ultrasound abdomen and cytomegalovirus PCR, IgM, IgG. If transplantation was due to hepatitis B infection then anti HBs level, HBsAg and anti-HBC were done. These patients also had HBV DNA as well. If transplantation was due to hepatitis $C$ then HCV RNA through PCR was done. All patients received tacrolimus 1-3 mg OD throughout the follow up, mycophenolate mofetil $500 \mathrm{mg} \mathrm{BD}$ for one year and steroid in a tapering dose for 3-6 months. Patients having transplantation secondary to hepatitis $B$ received hepatitis $B$ immunoglobulins every month according to anti-HBs level, in addition to lamivudine. Liver biopsy was not performed in any patients post liver transplant because of local beliefs and refusal for the consent for it.

\section{RESULTS}

Out of 30 patients, the sex distribution and etiology for liver transplantation is shown in Table I. Total nine patients remained well and didn't develop any major complication during follow up. Remaining 21 patients developed 1 or more complications as in Table II. During our follow up only 5 patients expired and among them 4 were males Table III. In our study 21 patients developed complications and 5 were expired. Remaining patients recovered well from complications and having reasonably good quality of life.

TABLE I:

SEX DISTRIBUTION AND ETIOLOGY OF INDICATION FOR LIVER TRANSPLANTATION

\begin{tabular}{|l|c|c|}
\hline & $\begin{array}{c}\text { Male } \\
(\mathbf{n = 2 3})\end{array}$ & $\begin{array}{c}\text { Female } \\
(\mathbf{n}=\mathbf{7})\end{array}$ \\
\hline Hepatitis B & 12 & $5^{\star}$ \\
\hline Hepatitis C & $7^{+}$ & 2 \\
\hline Autoimmune Hepatitis & 1 & --- \\
\hline Non Alcoholic Steatohepatitis & 1 & --- \\
\hline Schistosomiasis & 1 & --- \\
\hline Idiopathic hepatic fibrosis & 1 & --- \\
\hline Giant Hemangioblastoma & --- & 1 \\
\hline
\end{tabular}

* One patient had combined infection of hepatitis B\&C

+ One patient had hepatocellular carcinoma with cirrhosis. Later on this patient presented with extrahepatic metastasis.

\section{TABLE II: COMPLICATIONS ENCOUNTERED DURING FOLLOW UP}

\begin{tabular}{|l|c|}
\hline \multicolumn{1}{|c|}{ Complications } & No. of Patients \\
\hline Diabetes Mellitus & 13 \\
\hline Biliary stricture & 6 \\
\hline Nephrotoxicity due to tacrolimus & 3 \\
\hline Relapse of Hepatitis C & 2 \\
\hline Generalized Septicemia & 2 \\
\hline Giant choledochal cyst & 1 \\
\hline CMV Hepatitis & 1 \\
\hline BOOP & 1 \\
\hline
\end{tabular}

TABLE III: CAUSES OF DEATHS

\begin{tabular}{|l|c|c|}
\hline \multicolumn{1}{|c|}{ Causes } & Male $(\mathbf{n = 4})$ & Female $(\mathbf{n = 1})$ \\
\hline Obstructive Jaundice & 2 & --- \\
\hline Relapse of hepatitis C & --- & 1 \\
\hline Boop & 1 & --- \\
\hline $\begin{array}{l}\text { Extra hepatic } \\
\text { metastatic illness due } \\
\text { to HCC }\end{array}$ & 1 & --- \\
\hline
\end{tabular}




\section{DISCUSSION}

During the past decade, survival rate after liver transplantation have improved a lot, with one year survival rate exceeding $85 \%$, and 5 year survival rate exceeding $70 \%$. Despite the success of liver transplantation severe medical problems in addition to rejection, are routinely encountered by physicians. Even with the improvement in immunosuppressive therapy, hepatic allograft rejection remains an important cause of morbidity and late graft loss in patients undergoing liver transplantation. Acute cellular rejection develops in $25-70 \%$ of liver transplantation receiving tacrolimus or cyclosporine. ${ }^{11}$ In our study we do not observed acute or late graft rejection as we were not able to perform liver biopsy even with deranged liver enzymes, due to local belief and no consent was given by any patients. Liver enzymes normalize with altering the dosage of immunosuppressive therapy. Recurrence of hepatitis B infection after liver transplantation is universal unless active prophylaxis with a combination of an antiviral and hepatitis B immunoglobulin is taken. ${ }^{12}$ The risk of recurrence is greatest in patients with high HBV DNA prior to liver transplantation. It can be reduced with the use of lamivudine or adefovir before liver transplantation. ${ }^{13}$ Recurrence of chronic hepatitis $\mathrm{C}$ is one of the most frequent causes of chronic graft loss in patients with liver transplantation. In recurrent $\mathrm{HCV}$, fibrosis is more severe, leading to graft rejection. ${ }^{14}$ This hepatic fibrosis is more severe in donors above age 60. No specific immunosuppressive treatment or treatment with interferon prior to liver transplantation affects the survival. ${ }^{15}$ In our study only 2 patients had relapse of hepatitis C. Despite the advances in immunosuppressive therapy in recent years, the morbidity and mortality due to infectious complications remains a major problem. In some centers infection is the most common cause of death after liver transplantation, though deaths related to infectious diseases in non-transplant setting have steadily decreased. ${ }^{16}$ Among the infections $80 \%$ were bacterial and $20 \%$ viral (mostly human herpes virus 6 ) ${ }^{17}$ Infections occurring immediately post-transplant are nosocomial pneumonia, candidal infection, intra-hepatic abscess, cholangitis, abdominal abscess and wound infection. ${ }^{18} \mathrm{CMV}$ is one of the most common pathogen causing infection during 1-6 months. It occurs approximately in $50-60 \%$ of patients. ${ }^{19}$ As compared to other data four of our patients developed different infections including CMV hepatitis, generalized septicemia and boop. Non-immunologic complications of liver trans- plantation can be divided into the following categories: Complications related to immunosuppressive medications including hypertension, diabetes mellitus, hyperlipidemia, renal insufficiency and bone disease. Technical factors involved in the transplant operation such as biliary obstruction or stricture. Approximately 60$70 \%$ of liver transplant recipient develop hypertension within the first year of transplantation. ${ }^{20}$ The cause of hypertension is multifactorial but it is mostly related to cyclosporine and corticosteroids. ${ }^{21}$ None of our patients developed hypertension, may be it is due to the reason that we used tacrolimus as an immunosuppressive agent. Reversible renal injury develops frequently in the early post-transplant period due to acute tubular necrosis or cyclosporine or tacrolimus toxicity. Risk factors for renal insufficiency includes calcineurin inhibitor, older age group, pre-transplant lower GFR, female sex, post operative acute renal failure, baseline diabetes and hypertension, HCV infection. There is conflicting data regarding nephrotoxicity due to tacrolimus or cyclosporin. Some patients may progress to end stage renal disease..$^{22}$ About 13$30 \%$ of patients with liver transplantation may develop diabetes mellitus. ${ }^{23}$ Diabetes mellitus is developed in $40 \%$ of our patients and this high incidence can be explained in part due to use of tacrolimus rather than cyclosporine as an immunosuppressant. ${ }^{24}$ Hyperlipidemia is common after liver transplantation, it occurs in $16-43 \%$ of patients. New onset hyperlipidemia is not found in our patients. Reason may be the same, as tacrolimus is less associated with hyperlipidemia. ${ }^{25}$ The most common biliary complications following liver transplantation are leaks and stricture, both of which appears to be more common in those undergoing live donor compared with cadavaric liver transplantation. ${ }^{26}$ Bile leaks tend to present early after transplantation, most often arising from the T-tube insertion site or occurring after $\mathrm{T}$ tube removal. ${ }^{27}$ Biliary stricture develops in approximately $9-15 \%$ of liver transplant recipient. $^{28,29}$ It is more often in live liver donor transplantation. ${ }^{30}$ Six patients developed biliary stricture in our research, though all of our patients had cadavaric liver transplantation.

\section{CONCLUSION}

It could be seen by reviewing data of our study that outcome for end stage liver disease patients is much better after liver transplantation resulting in a reasonably good quality of life, provided complications are detected and treated promptly. The cost of surgery, 
availability of donor organs, continuous post transplantation care and subsequent follow up is too expensive. In our study as all the expenses were borne by the Omani Government, the post transplantation follow up was followed as per standard international protocol.

\section{REFERENCES}

1. Starzl TE, Marchiano TL, Von Kaulla KN. Homo transplantation of the liver in humans. Surg Gynaecol Obstet 1963; 117-659.

2. Multimer D. Liver Transplantation. Medicine International, Liver Disorders Number 2006; 07(1):1058.

3. Dienstag JL. Liver transplantation. In: Harrison's Principles of Internal Medicine $16^{\text {th }}$ edition Vol II; 2005: 1873-80.

4. Carithers RL Jr. Liver transplantation. Liver Transpl 2000; 122.

5. Malago M, Rogiers X, Broclsch CE. Liver splitting and living donor techniques. Br Med Bull 1997; 53: 860.

6. Lucey MR, Brown KA, Everson GT. Minimal Criteria for placement of adults on the liver transplant waiting list. Transplantation 1998; 66: 956.

7. Kamath PS. A model to predict survival in patients with end stage liver disease. Hepatology 2001; 33.

8. Wiesner R, Edwards E, Freeman R. Model for end-stage liver disease (MELD) and allocation of donor livers. Gastroenterology 2003; 124:91-6.

9. Laurence S, Friedman MD. Liver, Biliary tract \& Pancreas In: eds. Current Medical Diagnosis and Treatment 2008; 556-609.

10. Torpy JM. JAMA patient page Liver transplantation JAMA 2006 May 10; 295 (18): 2208.

11. Wiesner RH, Demetris J, Belle SH. Acute hepatic allograft rejection: Incidence, risk factors and impact on out come. Hepatology 1998; 28: 638.

12. Poordad FF. Liver transplant and recurrent disease. Clin Liv Dis 2004; 8: 461-73.

13. Marzano A, Lampertico $P$, Mazzaferro V. Prophylaxis of hepatitis $B$ virus recurrence after liver transplantation. J. Hepatol 2005; 42(Supp 2): A 132.

14. Berenguere M, Ferrell L, Watson J. HCV related fibrosis progression following liver transplantation: increase in recent years. J Hepatol 2000; 32: 67384.

15. Starvitz RT, Shiffmann ML, Sanyal AT. Effects of interferon treatment on liver histology and allograft rejection in patients with recurrent hepatitis $\mathrm{C}$ following liver transplantation. Liver Transpl 2004; 10: 850-8.

16. Toberson M, Jinzhou W, Nichols L. Causes of death in autopsied liver transplantation patients. Mod Pathol 1998; 11: 37.

17. Chang FY, Singh N, Gayowski T. Fever in liver transplant recipients. Changing spectrum of etiologic agents. Clin Infec Dis 1998; 26: 59.

18. Fishman JA, Rubin $\mathrm{RH}$. Infection in organtransplant recipients. N Eng J Med 1998; 338: 1741.

19. Das A. Cost effectiveness of different strategies of cytomegalovirus prophylaxis in orthotopic liver transplant recipients. Hepatology 2000; 31:311.

20. Sheiner PA, Magliocca JF, Bodian CA et al. Long term medical complication in patients surviving 5 years after liver transplant. Transplantation 2000; 69: 781.

21. European FK 506 Multicenter Liver Study Group. Randomized trial comparing tacrolimus (FK 506) and cyclosporine in prevention of liver allograft rejection. Lancet 1994; 344:423.

22. Ojo AO, Held PJ, Port FK. Chronic renal failure after transplantation of a non renal organ. $\mathrm{N}$ Engl J Med 2003; 349:931.

23. Bigam DL, Pennington Bigam DL, Pennington JJ, Carpentier A. Hepatitis C-related cirrhosis. A predictor of diabetes after liver Tansplantation. Hepatology 2000; 32:87.

24. Woodward RS, Schnit MA, Baty J, Lowell JA, Lopez-Rocaf-ort L, Haider S. Incidence and cost of new onset diabetes mellitus among US wait listed and transplanted allograft recipients. Am J Transplant 2003; 3: 590-8.

25. Manzarbeitia C, Reich DJ, Rothstein KD. Tacrolimus conversion improves hyperlipidaemic states in stable liver transplant recipients. Liver Transpl 2001; 7: 93.

26. Fondfevila C, Ghobrial RM, Fuster J. Biliary complications after adult living donor liver transplantation. Transplant Proc 2003; 35: 1902.

27. Lake JR. Long term management of biliary tract complications. Liver Transpl Surg 1998; 1: 45.

28. Rerknimitr R, Sherman S, Fogel EL. Biliary tract complications after orthotopic liver transplantation with choledocholedochostomy anastomosis. Endoscopic findings and results of therapy. Gastrointes Endosc 2002; 55: 224. 
29. Rizk RS, Mc Vicar JP, Emond MJ et al. Endoscopic management of biliary strictures in liver transplant recipients. Effect on patient and graft survival. Gastrointes Endosc 1998; 47: 1128.
30. Shah JN, Ahmed NA, Shetty K. Endoscopic management of biliary compolications after adult living donor liver transplantation. Am J Gastroenterol 2004; 99: 1291.

\section{AUTHOR AFFILIATION:}

Dr. Aftab Ahmed Siddiqui (Corresponding Author)

Head of the Department of Medicine

Liaquat College of Medicine and Dentistry

Darul-Sehat Hospital

Karachi, Sindh-Pakistan.

\section{Dr. Rakhshinda Jabeen}

Assistant Professor of Medicine

Liaquat College of Medicine and Dentistry

Darul-Sehat Hospital

Karachi, Sindh-Pakistan.

\section{Dr. Moin Ahmed Ansari}

Consultant Psychiatrist

Liaquat National Hospital

Karachi, Sindh-Pakistan.

\section{Dr. Babar Bashir}

Senior Registrar Medicine

Liaquat College of Medicine and Dentistry

Darul-Sehat Hospital

Karachi, Sindh-Pakistan.

\section{Dr. Saeed Ahmed}

Registrar Gastroenterology/ Medicine

Sultan Qaboos University Hospital

Al-Khod Muscat Oman.

\section{Dr. Masoud Bakheet Khashoob}

Sr. Consultant Gastroenterologist/ Director General

Sultan Qaboos University Hospital

Al-Khod Muscat Oman. 